\title{
ON ITERATED AND BILINEAR INTEGRAL HARDY-TYPE OPERATORS
}

\author{
Vladimir D. Stepanov and Guldarya E. Shambilova
}

Abstract. We characterize the weighted inequalities on Lebesgue cone of all nonnegative functions on the semi-axis for iterated integral operators with Oinarov kernels.

Mathematics subject classification (2010): 26D10, 46E20.

Keywords and phrases: Iterated Hardy-type operators, weighted Lebesgue space.

\section{REFERENCES}

[1] M. I. Aguilar Cañestro, P. Ortega Salvador, C. Ramírez Torreblanca, Weighted bilinear Hardy inequalities, J. Math. Anal. Appl., 387 (2012), 320-334.

[2] A. Gogatishvili, R. Mustafayev and L.-E. Persson, Some new iterated Hardy-type inequalities, J. Function Spaces Appl. (2013), Art. ID 734194, 30 pp.

[3] A. Gogatishvili, R. Mustafayev and L.-E. Persson, Some new iterated Hardy-type inequalities: the case $\theta=1$, J. Inequal. Appl. (2013), 2013:515.

[4] A. Gogatishvili and R. Mustafayev, Weighted iterated Hardy-type inequalities, Math. Inequal. Appl. 20 (2017), 683-728.

[5] A. Gogatishvili And V. D. Stepanov, Reduction theorems for weighted integral inequalities on the cone of monotone functions, Russian Math. Surv. 68 (2013), 597-664.

https://www.researchgate.net/profile/

Amiran Gogatishvili publication/259182428 Reduction theorems for weighted integral inequalities on the cone of monotone functions/ links/02e7e52a324deabfeb000000.pdf

[6] P. Jain, S. Kanjilal1, V. D. Stepanov and E. P. Ushakova, Bilinear Hardy-Steklov operators, Math. Notes. 104 (2018), 823-832.

[7] M. K ̌̌EPELA, Integral conditions for Hardy-type operators involving suprema, Collect. Math. 68 (2017), 21-50.

[8] M. Ǩ̌EPELA, Bilinear weighted Hardy inequality for nonincreasing functions, Publ. Mat. 61 (2017), $3-50$.

[9] M. KŘEPela, Iterating bilinear Hardy inequalities, Proc. Edinb. Math. Soc. (2) 60 (2017), no. 4, 955-971.

[10] M. Ǩ̌EPELA, Boundedness of Hardy-type operators with a kernel: integral weighted conditions for the case $0<q<1 \leqslant p<\infty$, Rev Mat. Complut.30 (2017), no. 3, 547-587.

[11] A. Kufner, L. Maligranda And L.-E. Persson, The Hardy inequality - About its history and some related results, Vydavatelsky Servis Publishing House, Pilsen (2007).

[12] A. Kufner, L.-E. Persson And N. SAmKo, Weighted inequalities of Hardy-type, World Scientific Publishing Co. Inc. New Jersey, (2017), xx+459 pp.

[13] R. Mustafayev, On weighted iterated Hardy-type inequalities, Positivity, 22 (2018), 275-299.

[14] R. OINARov, Two-sided estimates of the norm of some classes of integral operators, Proc. Steklov Inst. Math. 204 (1994), 205-214.

https://www.researchgate.net/publication/ 273574851 Two-sided estimates of the norm of some classes of integral operators

[15] L.-E. Persson, G. E. Shambilova and V. D. Stepanov, Hardy-type inequalities on the weighted cones of quasi-concave functions, Banach J. Math. Anal. 9 (2015), no. 2, 21-34.

[16] L.-E. Persson, G. E. Shambilova And V. D. Stepanov, Weighted Hardy-type inequalities for supremum operators on the cones of monotone functions, J. Inequal. Appl. (2016), 2016:237, 18 p. 
[17] D. V. Prokhorov, On a weighted inequality for a Hardy-type operator, Proc. Steklov Inst. Math. 284 (2014), 208-215. https://doi.org/10.1134/S0081543814010155

[18] D. V. Prokhorov, On a class of weighted inequalities containing quasilinear operators, Proc. Steklov Inst. Math. 293 (2016), 272-287. https://doi.org/10.1134/S0081543816040192

[19] D. V. Prokhorov and V. D. Stepanov, On weighted Hardy inequalities in mixed norms, Proc. Steklov Inst. Math. 283 (2013), 149-164. https://link.springer.com/content/pdf/10.1134/S0081543813080117.pdf

[20] D. V. Prokhorov AND V. D. Stepanov, Weighted inequalities for quasilinear integral operators on the semi-axis and applications to Lorentz spaces, Sbornik: Mathematics 207 (2016), no. 8, 135162. https://arxiv.org/pdf/1602.04884.pdf

[21] D. V. Prokhorov, V. D. Stepanov and E. P. Ushakova, Hardy-Steklov integral operators: Part I, Proc. Steklov Inst. Math. 300, Suppl. 2 (2018), S1-S112.

DOI: $10.1134 / \mathrm{S} 008154381803001 \mathrm{X}$

Part II, Proc. Steklov Inst. Math. 302, Suppl. 1 (2018), S1-S61. DOI: $10.1134 / \mathrm{S} 0081543818070015$

[22] H. L. Royden, Real analysis, Third edition, Macmillan Publishing Company, (New York, 1988).

[23] G. E. Shambilova, The weighted inequalities for a certain class of quasilinear integral operators on the cone of monotone functions, Sibir. Math. J. 55 (2014), no. 4, 745-767. https://doi.org/10.1134/S0037446614040168

[24] V. D. Stepanov, Weighted norm inequalities of Hardy type for a class of integral operators, J. London Math. Soc. (2) 50 (1994), no. 1, 105-120.

[25] V. D. STEPANov AND G. E. Shambilova, Boundedness of quasilinear integral operators on the cone of monotone functions, Sib. Math. J. 57 (2016), 884-904. https://doi.org/10.1134/S0037446616050190

[26] V. D. Stepanov And G. E. Shambilova, On the boundedness of quasilinear integral operators of iterated type with Oinarov's kernel on the cone of monotone functions, Eurasian Math. J. 8 (2017), 47-73.

[27] V. D. Stepanov and G. E. Shambilova, On weighted iterated Hardy-type operators, Anal. Math. 44 (2018), no.2, 273-283.

[28] V. D. Stepanov and G. E. Shambilova, Reduction of weighted bilinear inequalities with integration operators on the cone of nondecreasing functions, Siberian Math. J., 59 (2018), no. 3, 505-522. https://doi.org/10.1134/S0037446618030047

[29] V. D. Stepanov AND G. E. Shambilova, Iterated integral operators on the cone of monotone functions, Math. Notes, 104 (2018), no. 3, 443-453. https://doi.org/10.1134/S0001434618090122 